\title{
Design of Hybrid Fuzzy-PI Controller for Sensorless Speed Control of Separately Excited DC Motor Drive
}

\author{
Anil Gunde, G. Devadasu, M.Vijayasaanthi
}

\begin{abstract}
Many industries use separately excited DC motors for torque control applications[1]. Because of its wide range of adjustment and easier control. Moreover, to test the novel control algorithms DC motor drive is used as system [2]. A sensor less control system is used in this paper to control its speed by using hybrid fuzzy PI Controller, and the speed of motor is estimated with the help of adaptive observer[4]. A Hybrid Fuzzy-PI Controller is proposed in this paper instead of a linear PI controller or Fuzzy Controller inroder improve the performance of motor[5]. Simulation results using MATLAB/SIMULINK shows that the Hybrid Fuzzy - PI control system performs well when compared with linear PI and Fuzzy controller technically.
\end{abstract}

Index Terms- Fuzzy controller, Linear PI Controller, separately excited DC motors, Speed sensor less control, Hybrid Fuzzy-PI Controller.

\section{INTRODUCTION}

Many industries use separately excited DC motors for torque control applications, DC motor drives are intended to control the speed and the situation with the utilization of sensors, for example, tacho generators[1]. several researches have proposed the control algorithms for speed sensor less DC motor control systems to reduce the cost [2]. Sensor less speed control of Seperatly excited DC Motor with Hybrid Fuzzy PI Controller is proposed in this paper inorder to improve the performance of DC motor.

\section{MATHEMATICAL MODEL OF SEPARATELY EXCITED DC MOTOR}

The Field windings of separately-excited DC motor are excited by separate external power supply, and armature circuit is separated from the power supply [3]. The dynamics of the separately-excited DC motor includes the following equations:

$$
\begin{aligned}
& U_{a}(t)=R_{a} i_{a}+L_{a} \frac{d i_{a}(t)}{d t}+e_{b}(t) \\
& e_{b}(t)=k \omega(t) \\
& T_{m}(t)=k i_{a}(t) \\
& \frac{d \omega(t)}{d t}=\frac{T_{m}(t)-T_{l}(t)}{J} e_{b}(t)
\end{aligned}
$$

Where

\section{Armature Parameters}

ua( $\mathrm{t}) \quad$ : voltage

Revised Version Manuscript Received on August 19, 2019.

Mr. Anil Gunde, Asst. Professor, Dept. of EEE, CMR College of Engineering \& Technology, Hyderabad, Telangana, India.

Prof. G. Devadasu, Professor, Dept. of EEE, CMR College of Engineering \& Technology, Hyderabad, Telangana, India.

M.Vijayasaanthi, Asst.Professor, Dept. of EEE, CMR College of Engineering \& Technology, Hyderabad, Telangana, India. ia( $t$ ) : current

eb ( t ) : Back EMF

$\mathrm{R}$ a : Resistance

La : Inductance

Mechanical Parameters

$\mathrm{T} \mathrm{t}(\mathrm{t})$ : Load torque

T m ( t ) : Electromechanical torque

$\mathrm{w}(\mathrm{t})$ : Angular velocity

k :Motor constant

J : Moment of inertia

Equations (i) to (iv), will give the block diagram of the separately-exited DC motor as [5].

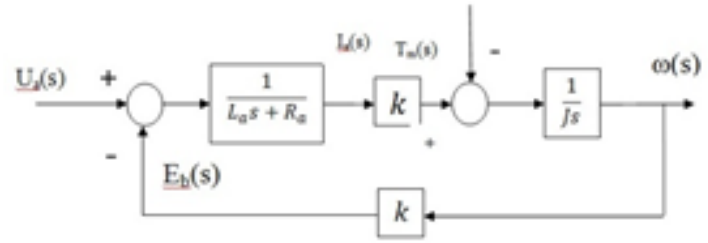

Fig.1. Block Diagram of separately-excited DC motor

\section{III.ADAPTIVE OBSERVER DESIGN}

To Estimate the unmeasurable states of the systems from the available states, we usually adopt the methodology of observer [3], here to estimate the speed of the separately excited dc motor adaptive observer is used from armature voltage and current as:

$$
\frac{d i_{a}(t)}{d t}=-\frac{\mathrm{R}_{\mathrm{a}}}{\mathrm{L}_{\mathrm{a}}} \mathrm{i}_{\mathrm{a}}(\mathrm{t})-\frac{\mathrm{k}}{\mathrm{L}_{\mathrm{a}}} \omega(\mathrm{t})+\frac{\mathrm{u}_{\mathrm{a}}(\mathrm{t})}{\mathrm{L}_{\mathrm{a}}}
$$

From above equation an adaptive observer can be determined to estimated speed $\omega^{\wedge}$ instead of measuring the actual speed ' $\omega$ ' as:

$$
\begin{aligned}
& \frac{d \hat{a}(t)}{d t}=-\frac{\mathrm{R}_{\mathrm{a}}}{\mathrm{L}_{\mathrm{a}}} \widehat{r}_{\mathrm{a}}(\mathrm{t})-\frac{\mathrm{k}}{\mathrm{L}_{\mathrm{a}}} \widehat{\omega}(\mathrm{t})+\mathrm{H}\left[\widehat{r}_{\mathrm{a}}(\mathrm{t})-\mathrm{i}_{\mathrm{a}}(\mathrm{t})\right]+\frac{\mathrm{u}_{\mathrm{a}}(\mathrm{t})}{\mathrm{L}_{\mathrm{a}}} \\
& \widehat{\omega}(t)=\left(k_{p}+k_{i} \int d t\right) e(t) \quad \text { with } k_{p}, k_{i}>0
\end{aligned}
$$

where ' $\mathrm{H}$ ' is known as feedback constant of adaptive observer \& the symbol ' $\wedge$ " denotes estimated values, the equation for the error is derived as follows from eqn (v) and eqn(vi):

$$
\frac{d e(t)}{d t}=\frac{d}{d t}\left[\hat{\imath}_{a}(t)-i_{a}(t)\right]
$$

$$
\begin{gathered}
=\frac{R_{a}}{L_{a}}\left[\widehat{\iota_{a}}(t)-i_{a}(t)\right]-\frac{k}{L_{a}}[\widehat{\omega}(t)-\omega(t)]+H\left[\widehat{\iota_{a}}(t)-i_{a}(t)\right] \quad \text { (viii) } \\
E(s)=\frac{\frac{k}{L_{a}}[\widehat{\omega}(s)-\omega(s)]}{s+\frac{R_{a}}{L_{a}}-H} \quad \text { (ix) }
\end{gathered}
$$


The Laplace transform of eqn (9) gives:

here

$$
E(s)=G(s)[\omega(s)-\widehat{\omega}(s)]
$$

$$
G(s)=\frac{\frac{k}{L_{a}}}{s+\frac{R a}{L_{a}}-H}
$$

Applying laplace transforms to eqn (vii) gives:

$$
\widehat{\omega}(s)=\left(k_{p}+k_{i} \frac{1}{s}\right) E(s) \quad \text { (xii) }
$$

From eqns (viii,ix, $\mathrm{x}$ ) the block diagram of speed estimation error as shown here in Fig(2), which is used to analyse the stability of the speed estimation [4].

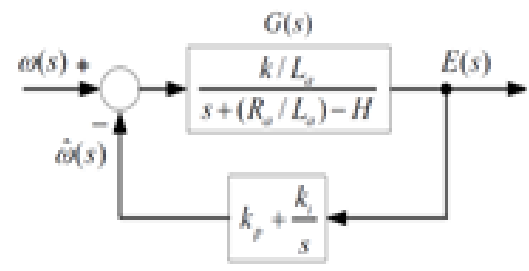

Fig.2. Estimation of Error in Speed of DC Motor From Fig 2, we have:

$$
\frac{\widehat{\omega}(s)}{\omega(s)}=\frac{G(s)\left(k_{p}+\frac{k_{i}}{s}\right)}{1+G(s)\left(k_{p}+\frac{k_{i}}{s}\right)}=\frac{\frac{k}{L_{a}}\left(k_{p} s+k_{i}\right)}{s^{2}+\left(\frac{R_{a}}{L_{a}}+\frac{k \cdot k_{P}}{L_{a}}-H\right) s+\frac{k \cdot k_{i}}{L_{a}}}
$$

Here if constant $\mathrm{H}$ satisfies the following condition then speed estimation is stable:

$$
H<\left(\frac{R_{a}}{L_{a}}+\frac{k \cdot k_{p}}{L_{a}}\right)
$$

\section{ADAPTIVE OBSERVER ALONG WITH FEEDFORWARD CONTROL}

\section{Feed forward Control:}

From the 'Ia' in eqn (iii), it is possible to control the electromagnetic torque since motor torque is proportional to armature current i.e T_m $(\mathrm{t})=\mathrm{ki}$ _a However, to control the motor torque feed forward control is used to imrove the accuracy in controlling the torque by using the ' $\mathrm{Va}$ ' applied to the motor as:

$$
u^{*}{ }_{a}(t)=R_{a} i_{a}^{*}(t)+k \widehat{\omega}(t)
$$

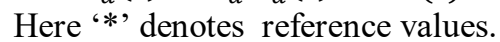

\section{Modified Feed forward Control:}

Modified feed forward controller is obtained when we add a feedback term $k_{f}\left[\hat{i}_{a}(t)-i_{a}(t)\right]$ to eqn $(\mathrm{xv})$ :

$u^{*}{ }_{a}(t)=R_{a} i^{*}{ }_{a}(t)+k \widehat{\omega}(t)+k_{f}\left[\hat{i}_{a}(t)-i_{a}(t)\right] \quad(\mathbf{x v i})$

Substituting $K_{f}=-L a H$

$$
\begin{gathered}
u^{*}{ }_{a}(t)=R_{a} i^{*}{ }_{a}(t)+k \widehat{\omega}(t)-L_{a} H\left[\widehat{i_{a}}(t)-i_{a}(t)\right](\mathbf{x v i i}) \\
\frac{u^{*}{ }_{a}(t)}{L_{a}}=\frac{R_{a}}{L_{a}} i^{*}{ }_{a}(t)+\frac{k}{L_{a}} \widehat{\omega}(t)-H\left[\widehat{i_{a}}(t)-i_{a}(t)\right](\mathbf{x v i i i )}
\end{gathered}
$$

From the applied voltage the dynamics of the adaptive observer is obtained as[8]-[9]:

$$
\frac{d \widehat{\iota_{a}}(t)}{d t}=\frac{R_{a}}{L_{a}}\left[i^{*}{ }_{a}(t)-\widehat{\iota_{a}}(t)\right]
$$

\section{EXPERIMENTAL RESULTS}

Sensorless control of seperatly excited DC Motor drive is implemented by using Matlab/Simulink, initially, the block diagram of closed loop feed forward control system with sensor less control is given by

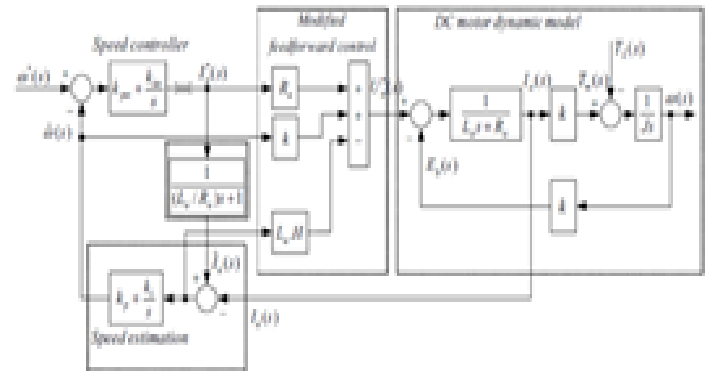

Fig.3. The sensor less DC motor control system with speed estimation and an adaptive observer

Initially PI Controller is used as controller, the simulink diagram is as follows

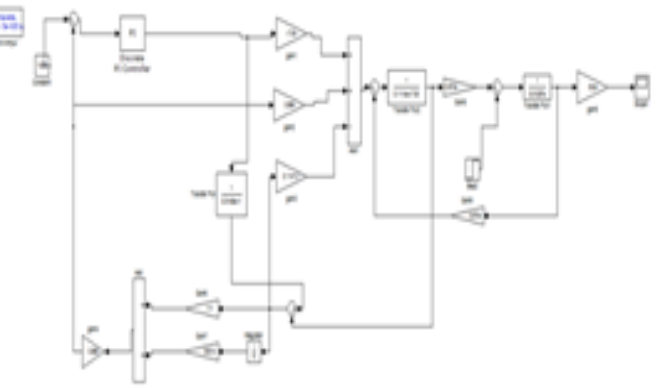

Fig: 4 Simulation diagram of sensorless speed control of DC Motor with PI Contoller in SIMULINK

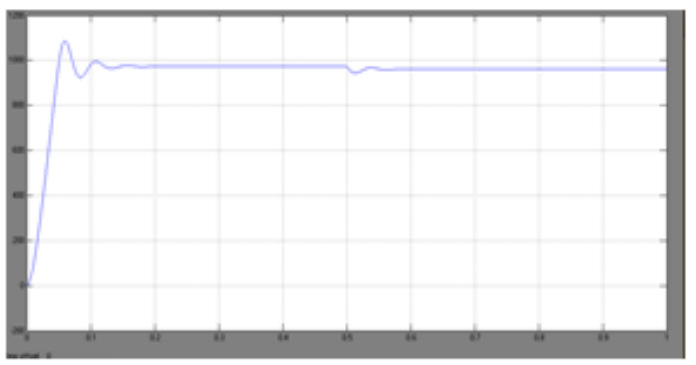

Fig: 5 performance of DC Motor when Reference Speed is 1000rpm with linear PI controller

Here the reference speed is given as 1000 RPM, in the response delay time (td),rise time(tr), settling time(ts) \& Peakover shoot $(\% \mathrm{Mp})$ is obtained as $0.03 \mathrm{sec}, 0.07 \mathrm{Sec}$, $0.2 \mathrm{Sec}, \& 10 \%$ respectively, even though the disturbance is applied at 0.5 Seconds yhe system is less affected by the disturbance. The response of the system is also observed with respect to PI Controller when the reference speed is changed to 1200 RPM. Response is as follows

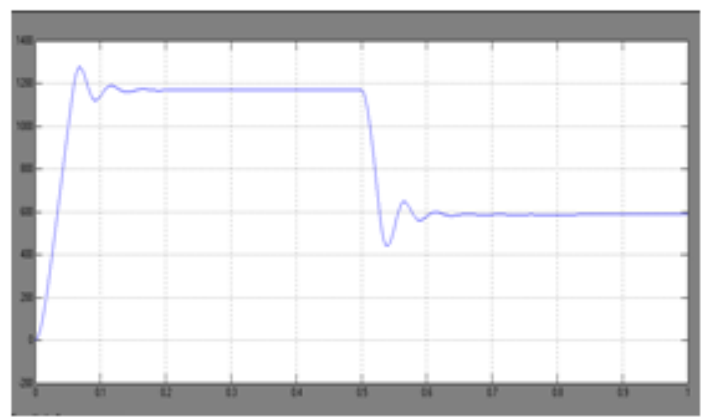

Fig: 6 Performance of DC Motor with PI Controller when reference speed is $1200 \mathrm{rpm}$ 
There after A fuzzy logic controller of Mamdani type is used to improve the performance of the system in matlab/ Simulink, there are two inputs for the controller i.e error and change in error, triangular membership fuctions are used for error and change in error with in the duration of -1 to 1 for both. For the output variable of FLC triangular membership functions are used with in the duration of -4 to 4 .

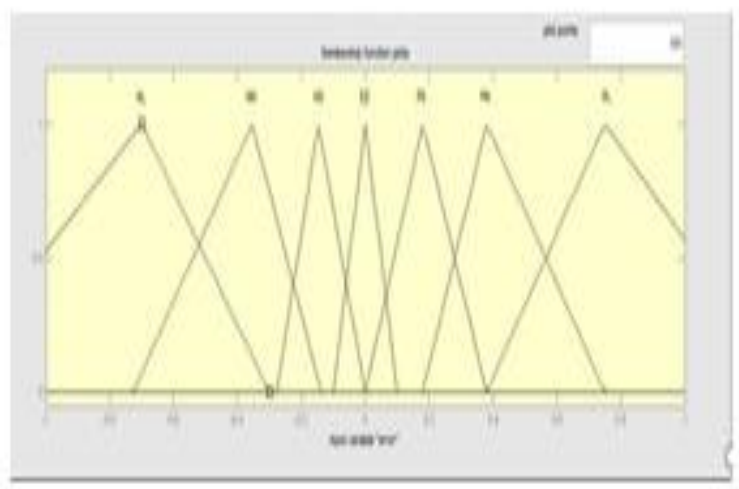

(a)

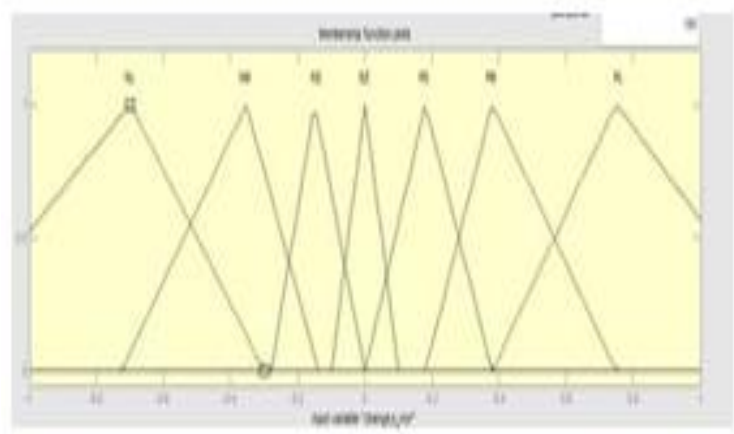

(b)

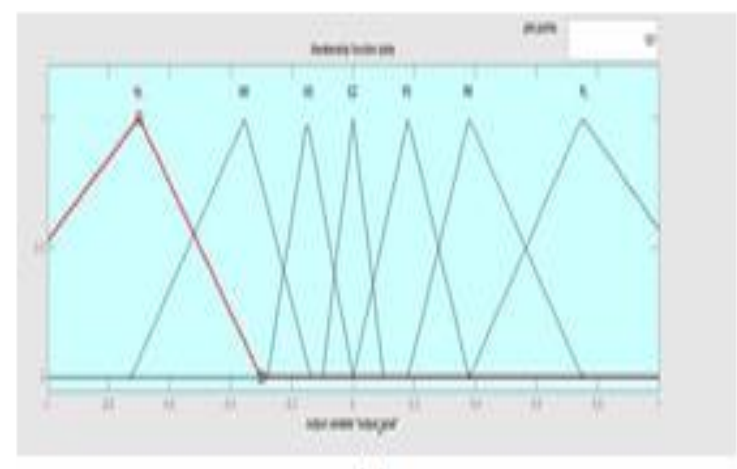

(c)

Fig: 7 input and output variables membership fuctions of Mamdani FLC

(a) Error 'e', (b) Change in error 'de'and (c) Output variable $u$.

For input variable and output variables seven membership functions in each they are named as Zero(Z), PS (Positive Small), PM(Positive Medeium), PB(Positive Big), NS(Negative Small), NM(Negative Medium), (NB)Negative Big [10]. Rule base for Mamdani FLC is

\begin{tabular}{|c|c|c|c|c|c|c|c|}
\hline e/de & NB & NM & NS & EZ & PS & PM & PB \\
\hline NB & NB & NB & NB & NB & NM & NS & NB \\
\hline NM & NB & NB & NB & NM & NS & EZ & NM \\
\hline NS & NB & NB & NM & NS & EZ & PZ & NS \\
\hline EZ & NB & NM & NS & EZ & PS & PM & EZ \\
\hline PM & NM & NS & EZ & PS & PM & PB & PS \\
\hline PS & NS & EZ & PS & PM & PB & PB & PM \\
\hline PB & EZ & PS & PM & PB & PB & PB & PB \\
\hline
\end{tabular}

Table :1 Rule Base for Mamdani FLC

Simulation Diagram of FLC Based Sensorless speed control system of separalty excited DC Motor is given by

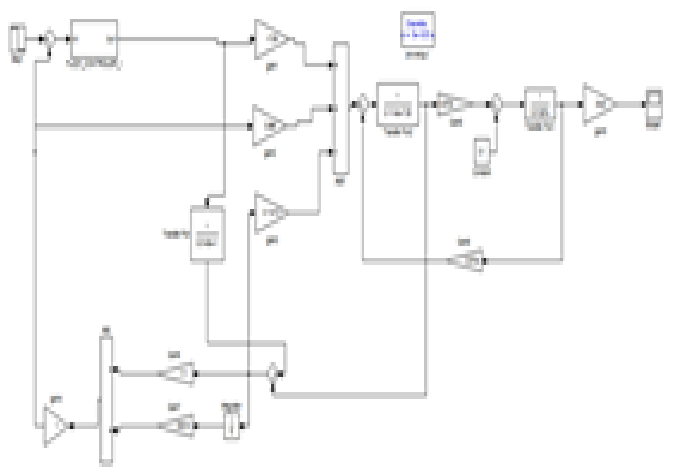

Fig :8 Simulation Diagram with FLC

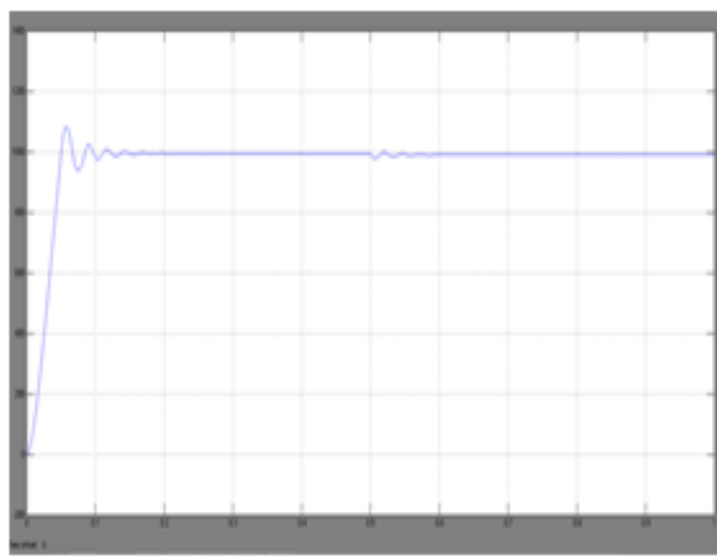

Fig: 9 Performance with FLC Controller when it is excited by 1000rpm

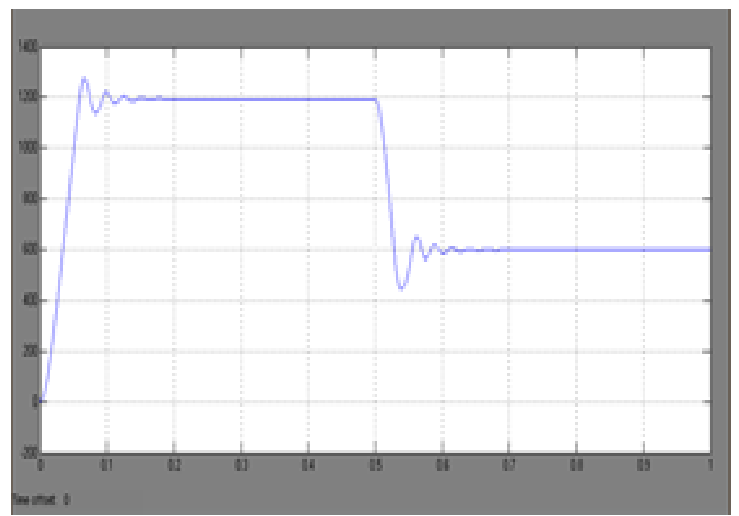

Fig: 10 Performance with FLC Controller when it is excited by 1200rpm

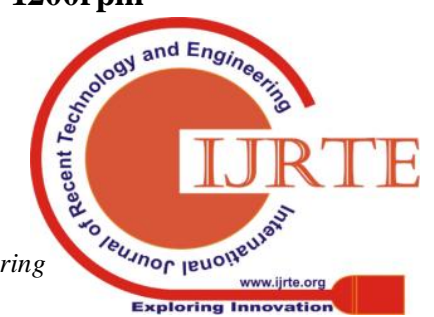




\section{DESIGN OF HYBRID FUZZY-PI CONTROLLER FOR SENSORLESS SPEED CONTROL OF SEPARATELY EXCITED DC MOTOR DRIVE}

From the the response it is observed that delay time (td),rise time(tr),settling time(ts) \& Peakover shoot (\%Mp ) is obtained as $0.04 \mathrm{sec}, 0.05 \mathrm{Sec}, 0.16 \mathrm{Sec}, \& 5 \%$ respectively, External disturbance is applied at 0.5 Seconds the system is less affected by the disturbance when compared with PI Controller.

Inorder to improve the system response further FLC in combination with PI Controller is used, since FLC is having good control for small variations in the parameters and PI is having good control for large variation of parameters.

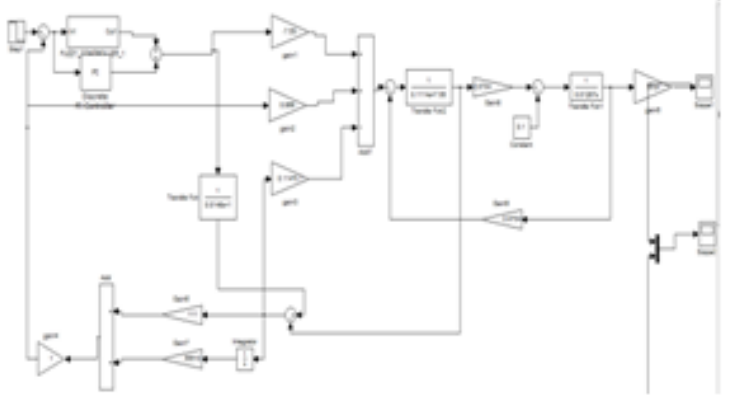

\section{Fig :11 Simulation Diagram with Hybrid FuzzyPI Controller.}

So it is expected that combination will give the better control performance in speed control of DC Motor.

From the response it is observed that delay time (td),rise time(tr),settling time(ts) \& Peakover shoot $(\% \mathrm{Mp})$ is obtained as $0.02 \mathrm{sec}, 0.04 \mathrm{Sec}, 0.13 \mathrm{Sec}, \& 8 \%$ respectively, the external disturbance is applied at 0.5 Seconds the system is less affected by the disturbance when compared with PI and FLC. The response is given by

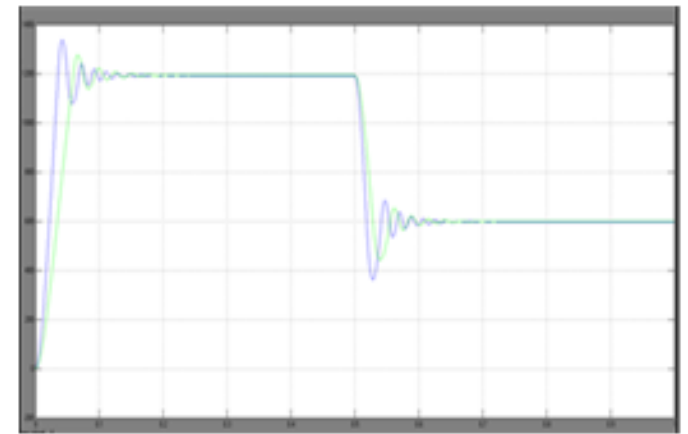

Fig: 12. Performance with Hybrid Fuzzy PI Controller when it is excited by 1200rpm

\section{CONCLUSION}

In this paper a speed-sensor less control system for DC motor system is proposed. Instead of measuring its speed, an adaptive observer along with modified feed forward control is also composed to estimate the original speed of the motor. The performance of the DC motor system is improved by introducing a hybrid Fuzzy PI controller for the speed control with the change of the reference speed or the change of the load torque when compared with liear PI controller and a Fuzzy controller[10]. This can be understood by the following Comparision table.

\begin{tabular}{|c|c|c|c|c|}
\hline & $\begin{array}{c}\text { Overshoot } \\
(\%)\end{array}$ & $\begin{array}{c}\text { Ts } \\
(\mathrm{sec})\end{array}$ & $\begin{array}{c}\text { Td } \\
(\mathrm{sec})\end{array}$ & $\begin{array}{c}\text { Tr } \\
(\mathrm{sec})\end{array}$ \\
\hline PI & 10 & 0.2 & 0.03 & 0.07 \\
\hline FLC & 5 & 0.16 & 0.04 & 0.05 \\
\hline $\begin{array}{c}\text { Hybrid } \\
\text { fuzzy PI }\end{array}$ & 8 & 0.13 & 0.02 & 0.04 \\
\hline
\end{tabular}

Tab: 2 Camparision B/w PI,FLC Hybrid FuzzyPI Controller Performance

\section{REFERENCES}

1. Fahimi, B.; Emadi, A.; Sepe, B., Jr., Position sensorless control, IEEE Industry Applications Magazine, Vol. 10, Issue 1, Jan-Feb 2004,40 - 47.

2. Son Nguyen Thanh, Cong Nguyen The, Hoa Ha Xuan, "Improved Performance of a Sensorless DC Motor Control using Fuzzy Logic" 978-1-4799-4653-2/14/\$31.00 () 2014 IEEE.

3. C.-T. Chi and S.-A. Yin, "Speed measurement of a general DC brushed motor based on sensorless method " IPEC, 2012Conference on Power \& Energy, pp. 332 - 337, 2012.

4. Rakan Khalil Antar, Ahmed A. Allu, Ahmed J. Ali, "Sensorless Speed Control of Separately Excited DC Motor Using Neuro-Fuzzy Controller" First International Conference of Electrical, Communication, Computer, Power and Control Engineering ICECCPCE'13/December17-18, 2013.

5. S. Praesomboon, S. Athaphaisal, S. Yimman, R. Boontawan, and K. Dejhan, "Sensorless speed control of DC servo motor using Kalman filter" 7th International Conference on Information, Communications and Signal Processing, pp. 1 - 5, 2009.

6. Z. An-ding, X. Jian-guo, and Z. Wen-min, "An Autotuning PID Control Algorithm for Sensorless DC Motors," 2010International Conference on Electrical and Control Engineering(ICECE), pp. 369 - 372, 2010.

7. C.L.Phillips and H.T.Nagle, "Digital Control System Analysis and Design”, Prentice Hall,New Jersey,1995.

8. C.L.Phillips and R.D.Harbor, "Feedback Control Systems",Prentice Hall,New Jersey,2000.

9. S. Yachiangkam, C. Prapanavarat, U. Yungyuen, and S. Po-ngam, "Speed-sensorless separately excited DC motor drive with an adaptive observer" TENCON 2004.

10. M. G. Simoes, "Fuzzy Logic Based Intelligent Control of a Variable Speed Cage Machine Wind Generation System," IEEETransactions on Power Electronics, vol. 12, pp. 87-95, 1997. 